\title{
Correction: A study of school-going children on neurobehavior and currently used agricultural pesticide exposure in the rural western cape, South Africa
}

Chetty-Mhlanga S, Basera W, Aqiel Dalvie M, et al. A study of school-going children on neurobehavior and currently used agricultural pesticide exposure in the rural western cape, South Africa. Occup Environ Med 2018;75(Suppl 1):A11.2. doi: 10.1136/oemed-2018ISEEabstracts.27

The following changes are required to abstract number A11.2 of the 'ISEE Young 2018, Early Career Researchers Conference on Environmental Epidemiology - Together for a Healthy Environment' supplement. (1) The first author should be listed as Shala Chetty-Mhlanga; (2) the third author should be listed as Mohamed Aqiel Dalvie; (3) Martin Röösli should be the last author (not Nicole Probst).

(c) Article author(s) (or their employer(s) unless otherwise stated in the text of the article) 2018. All rights reserved. No commercial use is permitted unless otherwise expressly granted.

Occup Environ Med 2018;75:474. doi:10.1136/oemed-2018-ISEEabstracts.27corr1

D) Check for updates 